\title{
Validity of conventional anthropometric techniques for predicting body composition in healthy Chinese adults
}

\author{
R. G. Eston DPE, F. Fu DPE*, L. Fung PhD ${ }^{+}$ \\ Division of Health and Human Performance, University of Wales, Bangor, *Department of Physical Education, \\ Hong Kong Baptist College, and ${ }^{+}$University of British Columbia, Department of Educational Psychology and \\ Special Education
}

\begin{abstract}
There is little information on the application of generalized prediction equations to ethnic groups other than Europeans and groups of European descent. The purpose of this study was to crossvalidate conventional equations on a group of 56 Chinese adults. Body density was assessed by underwater weighing and also predicted by equations which use a combination of selected skinfolds biceps, triceps, pectoral, subscapular, abdominal, suprailiac, thigh and calf. There were significant correlations $(P<0.01)$ between the various methods of predicting percentage fat. However, analysis of variance revealed significant differences $(P<0.01)$ between mean values. In the men, the Jackson and Pollock equation underestimated, and the Durnin and Womersley equation overestimated, the percentage fat predicted by underwater weighing. The best predictor site in this group was the medial calf skinfold $(r=0.81)$, which is not included in either equation. In the women, the best predictor sites were the triceps, suprailiac and thigh. As these sites are also used in the Jackson et al. equation, it is not surprising that there was no difference between the prediction of percentage fat by this equation and underwater weight. It is concluded that the Durnin and Womersley and Jackson and Pollock equations tend to overestimate and underestimate, respectively, the percentage fat in Chinese men. Alternative equations which use the calf skinfold may be more appropriate for this ethnic group. In Chinese women, there appears to be good agreement between Jackson and Pollock and hydrodensitometric estimations of percentage fat.
\end{abstract}

Keywords: Chinese, hydrodensitometry, skinfolds, percentage fat prediction

Simple anthropometric indices are frequently used to assess the body composition of selected populations. Perhaps the most frequently used equations are the skinfold equations of Durnin and Womersley ${ }^{1}$, Jackson and Pollock ${ }^{2}$ and Jackson, Pollock and Ward ${ }^{3}$. The equation of Durnin and Womersley uses the log sum of the biceps, triceps, subscapular and suprailiac folds and is based on a large sample of the Scottish

Address for correspondence: R. G. Eston, Ffriddoedd Building, Victoria Drive, Bangor, Gwynedd LL57 2EW, UK population. The accuracy of the equation (standard error of estimate (s.e.e.)) is reported to be about $3.5 \%$ for women and $4.0 \%$ for men. These equations appear to be satisfactory when cross-validated on average men $^{2}$, average women ${ }^{3}$, male athletes ${ }^{4}$ and female athletes ${ }^{5}$. Cadaver data, such as that derived from the Brussels study ${ }^{6}$ has revealed the importance of including observations from the lower limb (for example, the front of the thigh, medial calf etc) in prediction equations. Mueller and Stallones ${ }^{7}$ reached a similar conclusion on the basis of principle component analysis. The quadratic equations of Jackson and Pollock ${ }^{2}$ and Jackson $\mathrm{et} \mathrm{al.}^{3}$ are based on the sum of three readings from the chest, abdomen and thigh for men and the triceps, suprailiac and thigh for women. The quadratic approach, like the logarithmic transformation, avoids the problem of an increase in variance at the extremes of the distribution, and is thus an effective method of estimating fat content in specialized groups such as athletes, when the average member of the sample has a low percentage body fat $^{8}$.

The above equations are described as 'generalized' as they can be applied to other groups with similar characteristics without bias or marked error in the estimation. There is, however, little information on their application to ethnic groups other than Europeans and groups of European origin. Asian populations make up a substantial proportion of the world's population yet there is less body composition data on these than on any other major population group. The purpose of this study was to crossvalidate the 'generalized' skinfold equations of Durnin and Womersley ${ }^{1}$, Jackson and Pollock ${ }^{2}$ and Jackson et al. ${ }^{3}$ on a group of healthy Chinese men and women.

\section{Subjects and methods}

Fifty-six healthy Chinese subjects (47 men and nine women) volunteered to participate in this investigation. The subjects were middle class, Hong Kong Chinese urban dwellers. All subjects were practising physical education teachers. Descriptive statistics of the group are shown in Table 1. 
Table 1. Descriptive statistics of subjects

\begin{tabular}{lcccc}
\hline & \multicolumn{2}{c}{ Men } & \multicolumn{2}{c}{ Women } \\
\hline Age (years) & $34.9(4.6)$ & $24.0-43.0$ & $30.3(2.0)$ & $27.0-33.0$ \\
Height (cm) & $170.0(4.6)$ & $162.0-179.0$ & $156.3(4.1)$ & $152.0-164.0$ \\
Weight (kg) & $66.1(8.0)$ & $52.0-86.0$ & $50.9(8.2)$ & $42.6-67.5$ \\
\hline
\end{tabular}

Values are mean(s.d.) range

\section{Procedures}

Measures of height (to the nearest $0.1 \mathrm{~cm}$ ) and weight (to the nearest $0.1 \mathrm{~kg}$ ) were obtained using a Detecto stadiometer and beam balance scale. The subjects were instructed to stand with an erect posture, centred on the platform with heels together and looking forward. Whole body density was assessed by the hydrodensitometry procedure. All subjects were weighed in a specially designed tank using a pathological scale (Chatillon, $0-5 \mathrm{~kg}$ ) to determine underwater weight. The highest consistent reading from a total of five trials was taken as underwater weight. Subjects were instructed to submerse their bodies completely in the sitting position, while exhaling the total vital capacity from the lungs. Residual volume was predicted from the equations of DaCosta ${ }^{9}$ which were derived from Chinese subjects. Body fat, expressed as a percentage of total body weight, was calculated from the equation of Brozek et al. ${ }^{10}$.

Measurements of subcutaneous adipose and skin thickness were made on the right side of the body at the following sites with the subjects in a relaxed standing position, unless otherwise stated: biceps, midpoint of the muscle belly on the anterior aspect of the arm; triceps, midpoint between the acromion and olecranon processes on the posterior aspect of the arm; subscapular, a fold taken on a diagonal line coming from the vertebral border to 1 to $2 \mathrm{~cm}$ from the inferior angle of the scapula; suprailiac, midaxillary line just above the iliac crest; abdominal, a vertical fold taken at a lateral distance of $2 \mathrm{~cm}$ from the umbilicus; thigh, a vertical fold on the anterior aspect of the thigh midway between the inguinal crease and the proximal border of the patella; calf, a vertical fold on the medial aspect of the calf at the level of the greatest circumference with knee flexed and supported at an angle of $90^{\circ}$; pectoral (men only), a diagonal fold taken at a point halfway between the nipple and the anterior axillary fold. All skinfolds were taken using Holtain (Crosswell, Crymych, UK) skinfold calipers. Two measurements were taken at each site and if a difference of greater than $2 \mathrm{~mm}$ was observed, a third measure was taken. The mean of the two measurements was used as the representative value for each site. Whole body density and percentage fat ${ }^{10}$ were also predicted from the skinfold equations of Durnin and Womersley ${ }^{1}$, Jackson and Pollock $^{2}$ and Jackson et al. ${ }^{3}$ (see Table 2).

Circumferences were also taken at the upper arm (at the level of the triceps skinfold); waist, the narrowest part of the torso as seen from the anterior aspect; buttocks, at the level of maximum circum-
Table 2. Body composition formulae

Jackson and Pollock (Men) ${ }^{2}$

$D=1.10938-0.0008267(X 1)+0.0000016(X 1)^{2}-0.0002574$ (age)

Jackson, Pollock and Ward (Women) ${ }^{3}$

$D=1.0994921-0.0009929(X 2)+0.0000023(X 2)^{2}-0.0001392$ (age)

where:

$X 1=$ sum of chest, abdomen and thigh

$X 2=$ sum of triceps, suprailiac and thigh

Durnin and Womersley'

Density $=a+b(X 4)$

where:

$X 4=\log$ sum of triceps, biceps, suprailiac and subscapular

\begin{tabular}{lccc}
\hline & \multicolumn{3}{c}{ Age (years) } \\
\cline { 2 - 4 } & $20-29$ & $30-39$ & $40-49$ \\
\hline Men & & & \\
$a$ & 1.1631 & 1.1422 & 1.1620 \\
$b$ & 0.0632 & 0.0544 & 0.070 \\
Women & 1.1599 & 1.1423 & 1.1333 \\
$a$ & 0.0717 & 0.0632 & 0.0612 \\
$b$ & & & \\
\hline
\end{tabular}

ference; thigh, at the level of the thigh skinfold measurement; calf, at the level of the calf skinfold measurement. All circumferences were measured with a Gulick anthropometric tape.

\section{Results}

Percentage fat estimated by hydrodensitometry correlated significantly with both skinfold techniques, with acceptable levels of accuracy, i.e. around $2 \%$ for the women and $3 \%$ for the men (Table 3). Correlations for both anthropometric techniques were higher for women than for men, particularly for the Jackson et $a l^{3}$ regression equation. However, analysis of variance indicated that there were significant differences $(P<0.01)$ between all three methods for men and between hydrodensitometry and Durnin and Womersley for women (Table 4). As expected, in all cases, the percentage fat estimate for men was lower than the corresponding value for women.

Means; standard deviations and ranges for skinfolds and circumferences are shown in Table 5. Correlations between the various anthropometric measures and hydrodensitometry are shown in

Table 3. Relationship between skinfold technique and hydrodensitometry in Chinese men and women

\begin{tabular}{llc}
\hline \multirow{2}{*}{ Technique } & \multicolumn{2}{c}{ Hydrodensitometry } \\
\cline { 2 - 3 } & $\begin{array}{c}\text { Men } \\
(n=47)\end{array}$ & $\begin{array}{c}\text { Women } \\
(n=9)\end{array}$ \\
\hline Jackson et al. $^{3}$ & $0.67(3.1)$ & $0.93(2.0)$ \\
Durnin and Womersley & $0.73(2.9)$ & $0.89(2.5)$ \\
\hline
\end{tabular}

Values are $r$ (s.e.e.) 
Table 6. All skinfolds correlated significantly with percentage fat estimates by hydrodensitometry in both groups. However, there were differences in the size of correlations between skinfolds. In the men's group, the best skinfolds were the calf, biceps and thigh. Circumferences were poor predictors in men.

Table 4. Comparison of percentage body fat in Chinese men and women by hydrodensitometry and conventional skinfold techniques

\begin{tabular}{lcc}
\hline Technique & $\begin{array}{c}\text { Men } \\
(n=47)\end{array}$ & $\begin{array}{c}\text { Women } \\
(n=9)\end{array}$ \\
\hline $\begin{array}{l}\text { Hydrodensitometry } \\
\text { Jackson and Pollock }\end{array}$ & $15.9(0.61)$ & $20.0(1.8)$ \\
$\begin{array}{l}\text { Jackson et al. }^{3} \\
\text { Durnin and Womersley }\end{array}$ & $11.7(0.61)$ & $18.5(2.0)$ \\
\hline
\end{tabular}

Values are mean(s.e.m.)

Table 5. Descriptive statistics of skinfolds and circumferences in Chinese men and women

\begin{tabular}{lrlrr}
\hline & \multicolumn{2}{c}{ Men $(n=47)$} & \multicolumn{2}{c}{ Women $(n=9)$} \\
\hline Skinfolds & & & & \\
Biceps & $4.6(1.3)$ & $2.6-8.0$ & $6.0(3.4)$ & $3.4-13.2$ \\
Triceps & $8.3(2.6)$ & $4.4-15.0$ & $13.3(4.6)$ & $9.2-21.0$ \\
Subscapular & $13.9(5.2)$ & $6.6-30.0$ & $17.3(7.9)$ & $10.2-35.8$ \\
Suprailiac & $9.5(5.1)$ & $3.5-26.0$ & $12.5(6.4)$ & $6.0-24.0$ \\
Abdominal & $17.2(7.8)$ & $5.3-39.0$ & $20.0(8.0)$ & $13.0-37.0$ \\
Thigh & $11.0(4.0)$ & $5.2-24.0$ & $19.5(5.1)$ & $10.2-28.2$ \\
Calf & $7.5(2.2)$ & $3.7-14.8$ & $10.4(3.6)$ & $5.4-15.4$ \\
Pectoral & $8.0(3.5)$ & $3.0-17.4$ & - & - \\
& & & & \\
Circumferences & & & & \\
Upper arm & $27.6(2.5)$ & $22.5-32.5$ & $23.2(3.1)$ & $19.0-30.0$ \\
Abdomen & $76.9(7.6)$ & $48.0-90.5$ & $67.0(8.1)$ & $58.0-82.0$ \\
Buttocks & $91.8(4.6)$ & $85.5-101.5$ & $89.0(5.7)$ & $83.0-97.5$ \\
Thigh & $52.4(3.9)$ & $45.0-60.5$ & $45.4(4.7)$ & $40.5-52.0$ \\
Calf & $36.5(2.5)$ & $32.0-43.0$ & $34.2(2.7)$ & $29.5-38.0$ \\
& & & & \\
\hline
\end{tabular}

Values are mean(s.d.) range

Table 6. Correlations of skinfolds and circumferences with percentage fat estimates from hydrodensitometry in Chinese men and women

\begin{tabular}{lcc}
\hline & Men $(n=47)$ & Women $(n=9)$ \\
\hline Skinfolds & & \\
Biceps & 0.68 & 0.74 \\
Triceps & 0.56 & 0.90 \\
Suprailiac & 0.57 & 0.72 \\
Subscapular & 0.53 & 0.88 \\
Abdominal & 0.64 & 0.79 \\
Thigh & 0.66 & 0.89 \\
Calf & 0.81 & 0.88 \\
Pectoral & 0.65 & - \\
& & \\
Circumferences & & 0.63 \\
Upper arm & 0.31 & 0.82 \\
Abdomen & 0.24 & 0.95 \\
Buttocks & 0.53 & 0.82 \\
Thigh & 0.32 & 0.86 \\
Calf & 0.13 & \\
& & \\
\hline
\end{tabular}

In the women's group, the best four predictors were the triceps, thigh, calf and suprailiac, respectively. Circumferences, particularly buttocks and calf, correlated significantly in this group.

\section{Discussion}

Chien et al. ${ }^{11}$ used densitometry to determine the body composition of 27 Taiwanese men and six women, mean age 31 years, and on a second occasion 12 years later. The correlation of sum of ten skinfolds with adipose tissue mass for all 66 data points was 0.93 . However, they did not attempt to develop an estimation equation nor to test those in the literature. Wang and $\mathrm{Kou}^{12}$ reported a regression equation for estimating percentage fat from triceps and subscapular skinfolds based on densitometrically determined percentage fat in 49 Taiwanese athletes. The correlation was 0.88. Earlier, Nagamine and Suzuki ${ }^{13}$ had produced equations for estimating body density from single untransformed skinfolds of 208 Japanese college men and women with correlations up to 0.80 . In addition, Parizkova ${ }^{14}$ has reported that the regressions of density and the sum of ten skinfolds in the Taiwanese subjects of Allen et al. ${ }^{15}$ were not significantly different from those of Czechoslovakian adults.

The above is the extent and scope of the data on Asian populations, restricted as it is to a few studies of small numbers of young men and women performed 20 years ago. However, it does demonstrate the possibility of estimating body composition from anthropometric measurements in Chinese and other Asian groups, and the possibility that equations derived on Europeans may be applicable to Asians.

However, in the present study, although the relationship between the predicted percentage fat by hydrodensitometry, Durnin and Womersley, and Jackson and Pollock techniques were significant in the men, there were significant differences between the three methods. The data indicated that the Jackson and Pollock equation underestimated and the Durnin and Womersley equation overestimated the percentage fat when compared with hydrodensitometry. It is perhaps pertinent to note that the best predictor of percentage fat in the men's group was the calf skinfold and that this site is not used by the equations of Jackson and Pollock and Durnin and Womersley. This may account for the discrepancies in percentage fat estimations. It was considered appropriate to sum various combinations of skinfolds, to square skinfolds and to transform the combinations to logarithmic equivalents to obtain the highest correlation coefficient. In all cases, the calf was retained. The best combination was the sum of raw scores of the calf and biceps, with a correlation of 0.82 and s.e.e. of $2.4 \%$. It should be noted, however, that the addition of the biceps increased $r$ by only 0.01 . One factor which contributes to high correlations between variables is the degree of heterogeneity or range of values associated with the variables. It is worth noting that the calf and biceps had the lowest degree of heterogeneity among the men's group. This provides evidence that the calf skinfold may be a good discriminator of percentage fat in Chinese men. 
For the calf alone, the equation produced was:

$$
\begin{aligned}
& \% \text { fat }=4.88+1.48 \text { (calf) } \\
& r=0.81 \text {, s.e.e. }=2.4 \% .
\end{aligned}
$$

As the calf skinfold was indicated as the best predictor of percentage fat for the men in this study, we undertook a further analysis on the dataset. Stepwise multiple regression analysis was applied to the skinfold data on a subsample of 32 randomly selected men, with percentage fat as predicted by hydrodensitometry as the dependent variable. The calf skinfold was selected as the best predictor in this subsample, and produced the regression equation:

$$
\% \text { fat }=5.87+1.37 \text { (calf) }
$$

$r=0.84$, s.e.e. $=2.1 \%$.

The predictive accuracy of this equation was then tested on the remaining 15 men by comparing the values from this equation with the values obtained by hydrodensitometry. Mean(s.e.e.) percentage fat predicted by the calf equation and by hydrodensitometry on this subsample was 15.6(2.5) and 14.8(4.3), respectively. A related $t$ test indicated that there was no significant difference between the means $(t=1.08)$. The $t$ test correlation between the two predictions was $r=0.76(P<0.01)$. This provided further evidence that the medial calf site was a particularly useful predictor of percentage fat in the men from this study.

In the women's group, correlations for both Jackson, Pollock and Ward, Durnin and Womersley and hydrodensitometry were highly significant, although the number of women in this sample was substantially lower, due to a reluctance of the women to enter the tank. Results should therefore be regarded appropriately. Nevertheless, the skinfolds which were the best predictors in the women's group were the triceps, thigh, calf and suprailiac, respectively, with correlations being equal to or exceeding 0.88. Both the Jackson et al. and Durnin and Womersley equations use at least two of these skinfold sites, and it is perhaps therefore not surprising that the predictive ability of these equations is better in Chinese women. In fact, it would appear that the Jackson et al. equation is ideally suited for Chinese women. The three best predictor sites were the same three sites used in this equation. It is notable that there was no significant difference between percentage fat estimated by this equation and that estimated by hydrodensitometry.

Although the general application of this study may be limited due to the relatively small number of subjects used, it does provide some interesting evidence that the calf site could be a particularly useful predictor of percentage fat in healthy Chinese men. Although this may be attributed to the relatively small number of subjects used in this study, Martin et al. ${ }^{6}$ have also observed that this site is one of the best predictors of total subcutaneous adipose tissue mass. It is concluded that the Durnin and Womersley and Jackson and Pollock equations tend to overestimate and underestimate, respectively, the percentage fat in Chinese men. Alternative equations which use the calf skinfold may be more appropriate for this ethnic group. In Chinese women, there appears to be good agreement between Jackson and Pollock and hydrodensitometric estimations of percentage fat.

It is perhaps pertinent to include a note of caution about the use of hydrodensitometry to estimate body composition. It is acknowledged that the assumptions underlying this technique may not be absolutely correct and appropriate for different ethnic groups. The assumption that the mean density $\left(1.1 \mathrm{~g} \mathrm{ml}^{-1}\right)$ and proportion of the lean compartment is constant is not tenable. The density and proportion of tissues that contribute to the lean mass (predominantly muscle and bone but also including other forms of connective tissue, nervous and epithelial tissue) must be known in order to derive a single value for density. The proportion of muscle tissue will vary from individual to individual. In one study, the density of bone tissue varied from 1.18 to $1.33 \mathrm{~g} \mathrm{ml}^{-1}$ and represented a range of 16.3 to $25.7 \%$ of the adipose tissue free mass ${ }^{16}$. Thus the assumptions with respect to the fat-free mass cannot be accepted without severe limitations. Adjustments have therefore been proposed for subgroups of the population. For example, Schutte et $a .^{17}$ have suggested a value of $1.113 \mathrm{~g} \mathrm{ml}^{-1}$ for the North American Black population. As far as we know, there are no such figures for the Chinese population, but there may well be differences which are equally attributable to ethnicity. It is therefore likely that the reliability of this method may be different for different ethnic groups.

\section{Acknowledgements}

The authors would like to thank Dr Nick Norgan of Loughborough University of Technology for his very helpful advice and comments on an earlier draft of this paper.

\section{References}

1 Durnin JVGA, Womersley J. Body fat assessed from total body density and its estimation from skinfold thickness: measurements in 481 men and women aged from 16 to 72 years. $\mathrm{Br}$ J Nutr 1974; 32: 77-97.

2 Jackson AS, Pollock ML. Generalized equations for predicting body density of men. B J Nutr $1978 ; 40 ; 497-504$

3 Jackson AS, Pollock ML, Ward A. Generalized equations for predicting body density of women. Med Sci Sports Exerc 1980; 12: $175-82$.

4 Sinning WE, Dolny DG, Little KD, Cunningham LN et al. Validity of generalized equations for body composition analysis in male athletes. Med Sci Sports Exerc 1985; 17: 124-30.

5 Sinning WE, Wilson JR. Validity of generalized equations for body composition in women athletes. Res Q Exerc Sport 1984; 55: 153-60.

6 Martin AD, Ross WD, Drinkwater DT, Clarys JP. Prediction of body fat by skinfold caliper: assumptions and cadaver evidence. Int J Obes 1985; 9(Suppl 1): 31-9.

7 Mueller WH, Stallones L. Anatomical distribution of subcutaneous fat: skinfold site choice and construction of indices. Hum Biol 1981; 53: 321-5.

8 Shephard RJ. Body Composition in Biological Anthropology. Cambridge, UK: Cambridge University Press, 1990: 58-9.

9 DaCosta JL. Pulmonary function studies in healthy Chinese adults in Singapore. Am Rev Respir Dis 1971; 104: 128-31.

10 Brozek J, Grande F, Anderson T, Keys A. Densitometric analysis of body composition: revisions of some basic quantitative assumptions. Ann NY Acad Sci 1963; 110: 113-40.

11 Chien S, Peng MT, Chen KP, Huang TF, Chang C, Fang HS. Longitudinal studies on adipose tissue distribution in human subjects. J Appl Physiol 1975; 39: 825-30. 
Anthropometric prediction of body composition in Chinese adults: R. G. Eston et al.

12 Wang WC, Kou DH. Estimation of body fat in Chinese young men. Aerospace Medicine 1974; 45: 307-9.

13 Nagamine S, Suzuki S. Anthropometry and body composition of Japanese young men and women. Hum Biol 1964; 36: 8-15.

14 Parizkova J. Body Fat and Physical Fitness. The Hague, The Netherlands: Martinus Nijhoff BV, 1977: 30.

15 Allen TH, Peng MT, Chen KP, Huang TF, Chang C, Fang HS. Prediction of total adiposity from skinfolds and the curvi- linear relationship between external and internal viscosity. Metabolism 1956; 5: 346-52.

16 Clarys JP, Martin AD, Drinkwater DT. Gross tissue masses in adult humans: data from 25 dissections. Hum Biol 1984; 56: 459-73.

17 Schutte JE, Townsend EJ, Huff J, Shoup RF, Malina RM. Density of lean body mass is greater in Blacks than in Whites. J Appl Physiol 1984; 456: 1647-9. 